\title{
Effects of shock and noise on running after training with partial or continuous reward*
}

\author{
JOHN SCULL \\ University of Sussex, Sussex, England
}

Rats were given partial or continuous reward in a runway, then continuous reward while either shock or loud noise was presented early in the runway on half of the trials. They were then given extinction. Shock produced conditioned suppression in the segment preceding its administration, a decrement in running immediately following it, and an increase in running speed in the last segment. Noise did not produce conditioned suppression but did produce an increase in speed following its administration. Partial reinforcement did not alter any of the effects of either stimulus but reliably increased resistance to extinction.

Similarity between the effects of punishment and frustration, as well as between their theoretical treatment, has been pointed out by several writers; they have suggested that a general theory of persistence can be formulated which includes resistance to frustration and punishment as special cases (Amsel, 1968; Banks, 1966; Martin, 1963; Wagner, 1966). The transfer of persistence from partial reward to punishment situations, suggested by such a theory, has been demonstrated (Brown \& Wagner, 1964; Ratliff \& Clayton, 1969): i.e., training which increases resistance to anticipation of one kind of disruption (anticipatory frustration) apparently increases resistance to anticipation of another disruption (fear of shock).

In these cases, however, the disruptive shocks and nonrewards were both presented at the end of the instrumental sequence. One possible further extension of this type of persistence theory would predict that (1) persistence training should increase resistance to disruption by fear of a strong stimulus presented at a different point in the response sequence, and (2) persistence training should reduce the effects of the disruptive stimulus itself, i.e., reduce external inhibition (Pavlov, 1927).

In the present experiment, rats were trained in a runway with either partial or continuous reward and then exposed to shock or loud noise while performing the running response for continuous reward. The response was then extinguished to provide evidence that the partial reward training had been effective in increasing resistance to extinction.

*This experiment was part of a PhD thesis submitted to the Department of Psychology, University of Toronto. The research was supported by Grants APA-72 from the National Research Council of Canada and GB-3772 from the National Science Foundation to Professor A. Amsel.

\section{SUBJECTS}

Forty male Wistar-strain albino rats, purchased from Woodlyn Farms, Guelph, Ont., served as Ss. They were 50-60 days of age at the start of the experiment.

\section{APPARATUS}

The runway was built of 1 -in. pine board covered with $1 / 4-i n$. clear Plexiglas, and the sides and bottom were lined with aluminum plates, with a $1 / 2$-in. gap between the plates to keep them electrically isolated so they could serve as shock electrodes. The runway was 63 in. long, 3 in. wide, and 4 in. deep. A gray startbox, 10 in. long, was separated from one end of the runway by a clear plastic guillotine door, and an unpainted metal guillotine door was located 15 in. from the other end of the runway. Reward was delivered by a Ralph Gerbrands pellet dispenser into a 2-in.-square foodcup recessed into the end of the runway. Photoelectric cells and lights were located at 1 - $\mathrm{ft}$ intervals along the runway, and standard electric timers recorded the time $S$ took to traverse each segment. Relay equipment made operation of the pellet dispenser, shock generator, and noise generator contingent on the breaking of photobeams.

White noise was delivered from a General Radio random-noise generator through a 6-in. speaker located above the center of the runway. The noise intensity was adjusted, using a General Radio sound-level meter, inside the runway. Shock was delivered into the two metal plates from a Grayson-Stadler constant-current shock generator

\section{PROCEDURE}

The experiment was a 2 by 2 factorial design. Ss were given either partial or continuous reward during acquisition. During the punishment test phase, half of each of these groups received either shock or noise in the second 1 - $\mathrm{ft}$ segment of the runway.
The Ss were handled and maintained on ad lib water and $10 \mathrm{~g}$ of Purina Lab Chow, beginning 28 days before the first day of training, and were assigned arbitrarily to the four groups. For the first 30 days, Ss were run in rotation in two squads of 20 each for four trials per day. They were kept in individual carrying boxes between trials. For the next 12 days, Ss were carried individually into the experimental room from their home cages. They were given two trials per day, with a minimum intertrial interval of $30 \mathrm{~min}$. The remainder of the experiment was again run with four trials per day.

All four groups received reward on every trial for the first 4 days of training. For the next 26 days, two groups continued to receive continuous reward, while the other two were given $50 \%$ reward. The partial reward groups were given two rewards each day in a random order. For the next 12 days, all groups were given two rewarded trials per day. After 2 days at two trials per day, the test phase was begun: half the Ss from each reward condition were given shock and half were given noise on one randomly selected trial each day. The disruptive stimuli were administered as soon as $\mathrm{S}$ broke the first photobeam, $1 \mathrm{ft}$ into the runway, and both stimuli were $0.5 \mathrm{sec}$ in duration. The shock intensity was $0.2 \mathrm{~mA}$, and the noise intensity was $90 \mathrm{~dB}$. After this test phase, all Ss were given 4 days of continuous reward and 7 days of nonrewarded extinction trials, again at four trials per day.

\section{RESULTS}

Running times in each segment of the runway were converted to speeds, and analyses of variance were performed on these transformed scores. During the first 4 days of continuous reward training, the only significant effect was that of increasing speeds with days of training $(p<.01)$. Early in partial reward training, the partial reward groups ran more slowly than the continuous reward groups, but by the end of training the groups did not differ in any measure. Analysis of variance of this phase yielded a significant $(\mathrm{p}<.01)$ Group by Day interaction in all runway segments except the last, as well as main effects of groups and days. There were no differences among groups in the 2 days of continuous reward that preceded the test phase.

During the test phase, different groups were either shocked or given a loud noise in the second 1 - $\mathrm{ft}$ segment of the runway. Figure 1 shows the development of suppression in the segment preceding stimulation as the test phase progressed. The group being shocked gradually showed suppression, 
while the group given noise did not. This was reflected in a significant Group by Day interaction $[F(4,144)=7.48, \quad p<.01]$. There were no significant effects or interactions involving percentage of reward.

The running speed on stimulated and nonstimulated trials for both stimulus groups in all five segments of the runway are shown in Table 1 . In the second segment, there were significant effects of stimulus group $[F(1,36)=17.51, \quad p<.01]$, type of trial $[F(1,36)=4.92, \quad p<.05]$, and the Stimulus Group by Type of Trial interaction $[F(1,36)=31.51$, p<.01]. Table 1 shows that the shocked group ran more slowly on all trials than the noise group and that, while shock produced a decrease in speed $(t=5.54, \quad d f=144, \quad p<.01)$, noise produced an increase $(t=2.38$, $\mathrm{df}=144, \mathrm{p}<.02$ ). In the three runway segments following stimulation, the noise group showed the same effect: faster running on stimulated than on nonstimulated trials. The shock group ran more slowly on stimulated trials in Segment $3 \quad(t=1.97, \quad d f=144$, $\mathbf{p}<.05)$, there was no difference between the two types of trials in Segment $4(t=0.78, d f=144)$, and in Segment 5 the shock group, like the noise group, ran faster on stimulated trials than on nonstimulated trials $(\mathrm{t}=4.92$, df $=144, \mathrm{p}<.05)$. This is reflected by the significant main effect of type of trial in Segment 5 $[F(1,36)=24.44, p<.01]$. There was neither a significant effect involving percentage of reward in any segment of the runway during the test phase nor any change in the effects of the stimuli as the test phase progressed.

In extinction, the partial reinforcement groups were more resistant to extinction than were the continuous reinforcement groups. This was reflected by significant effects of reward groups $[F(1,36)=4.50$, p <.05, in the start, and $F(1,36)=9.52,13.49,14.99,11.08$, $\mathrm{p}<.01$, in the other segments] and Reward Groups by Days $[F(6,216)=16.18,18.61, \quad 27.92$, $25.59,22.58, \mathrm{p}<.01]$. There were no differences between the shock and noise groups in extinction.

\section{DISCUSSION}

There was no difference between the partial reward and continuous reward groups in their reaction to the presentation of shock or loud noise

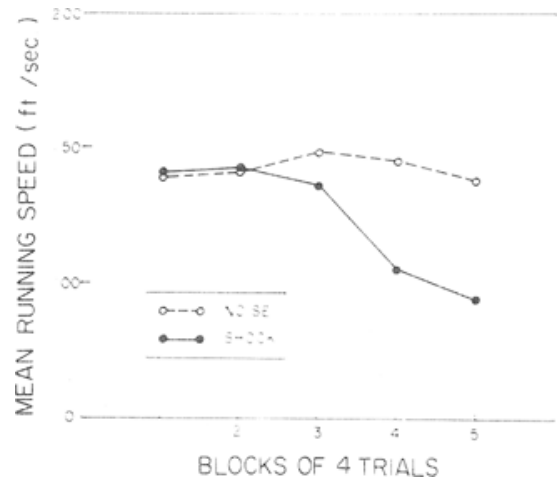

Fig. 1. Running speeds of the two stimulus groups in Measure 1 during the punishment test phase.

early in the runway. While the transfer of persistence between anticipatory frustration and fear of goalbox shock has previously been demonstrated (Brown \& Wagner, 1964; Ratliff \& Clayton, 1969), there does not appear to be transfer of persistence from anticipatory frustration to the immediate effects of shock or loud noise presented during the instrumental response. The failure to find a difference between the partial and continuous reward groups in the suppression caused by fear of shock in the first segment of the runway further suggests that transfer of persistence may be restricted to cases where the anticipated aversive events occur at the same location in space or at the same point in the response sequence.

The two disruptive stimuli had different unconditional effects on behavior. While shock slowed running speeds, noise caused a reliable increase.

Table 1

Mean Running Speeds (in Feet Per Second) on Stimulated and Nonstimulated Trials

\begin{tabular}{|c|c|c|c|}
\hline Measure & & $\begin{array}{c}\text { No } \\
\text { Stimulus } \\
\text { Trials }\end{array}$ & $\begin{array}{c}\text { Stimulus } \\
\text { Trials }\end{array}$ \\
\hline 1 & $\begin{array}{l}\text { Shock Group } \\
\text { Noise Group }\end{array}$ & $\begin{array}{l}1.22 \\
1.40\end{array}$ & $\begin{array}{l}1.26 \\
1.46\end{array}$ \\
\hline 2 & $\begin{array}{l}\text { Shock Group } \\
\text { Noise Group }\end{array}$ & $\begin{array}{l}2.43 \\
3.30\end{array}$ & $\begin{array}{l}1.93 \\
3.52\end{array}$ \\
\hline 3 & $\begin{array}{l}\text { Shock Group } \\
\text { Noise Group }\end{array}$ & $\begin{array}{l}2.51 \\
3.22\end{array}$ & $\begin{array}{l}2.33 \\
3.68\end{array}$ \\
\hline 4 & $\begin{array}{l}\text { Shock Group } \\
\text { Noise Group }\end{array}$ & $\begin{array}{l}2.73 \\
3.31\end{array}$ & $\begin{array}{l}2.80 \\
4.00\end{array}$ \\
\hline 5 & $\begin{array}{l}\text { Shock Group } \\
\text { Noise Group }\end{array}$ & $\begin{array}{l}2.09 \\
2.23\end{array}$ & $\begin{array}{l}2.23 \\
2.57\end{array}$ \\
\hline
\end{tabular}

The differential conditioned suppression found in the first runway segment suggests that the difference in immediate effect was the result of the shock being functionally more intense than the noise. However, there is a striking similarity between these results and the effect obtained by LoLordo (1967) in a comparison of the unconditional effects of shock and loud noise on a baseline of shock-avoidance responding. He found that shock caused acceleration in avoidance rate, while noise produced deceleration, the opposite of the result obtained on a baseline of rewarded behavior in this experiment. These results may reflect different unconditional responses to shock and noise or simply differences in functional intensity.

Finally, the increase in speed produced by both shock and noise in the last segment of the runway should be noted. This increase probably represents either an increase in motivation following aversive stimulation or the effects of escaping from the location of the aversive stimulation (Bertsch \& Leitenberg, 1970).

\section{REFERENCES}

AMSEL, A. Behavioral habituation and a general theory of persistence. Invited address presented at the Canadian Psychological Association meeting. Calgary, June 1968.

BANKS, R. K. Persistence to continuous punishment following intermittent punishment training. Journal of Experimental Psychology, 1966, 71, 373.377.

BERTSCH，G.J. \& LEITENBERG, H. A "frustration effect" following electric shock. Learning \& Motivation, 1970.1, $150-156$.

BROWN, R. T., \& WAGNER, A. R. Resistance to punishment and extinction following training with shock or nonreinforcement. Journal of Experimental Psychology, 1964, 68, 503-507.

LoLORDO. V. Summation of fear of different aversive events. Journal of Comparative \& Physiological Psychology, $1967,64,154-158$.

MARTIN, B. Reward and punishment associated with the same goal response: A factor in the learning of motives. Psychological Bulletin, 1963, 60, 441-451.

PAVLOV, I. P. Conditioned reflexes. London: Oxford University Press, 1927. RATLIFF、R、G., \& CLAYTON, K. N Runway extinction as a joint function of acquisition reward percentage and extinction punishment intensity. Journal of Experimental Psychology, 1969,80, 574-576.

WAGNER, A. R. Frustration and punishment. In R. N. Haber (Ed.), Current research in motivation. New York: Holt, Rinehart, \& Winston, 1966. 